\title{
Supporting students as learners: two questions concerning pedagogic practice
}

\section{Gavin Fairbairn}

Leeds Metropolitan University, UK

(This opinion piece is the second of two related articles, the first of which appeared in Issue 3 of the JLDHE, 2011)

\begin{abstract}
Probably the most important thing that any of us who work in higher education can do, is to help our students to say themselves more clearly, by communicating what they know, what they think about what they know, and why they think it. After all, it is by engaging skilfully in the processes of academic communication, whether in written or spoken forms, that they can persuade us that they have learned something and have thought about what they have learned. What a pity, then, that most university teachers do so little to help students to develop the skills necessary to write well. In this article I discuss two ways in which I have found I can help students in their development as writers capable of engaging, informing and challenging their readers. In doing so, I acknowledge some possible criticisms.
\end{abstract}

\section{Introduction}

There are a couple of aspects of my pedagogic practice that I think are really worthwhile, but for which I am sometimes criticised. The first stems from my belief that feedback about students' work is always best shared verbally, and even better when it is shared in a group context. The second stems from my belief that the best way to enable students to develop as academic writers is to enter into a kind of partnership with them in the development of their texts. 


\section{Feedback in a group setting}

Sometimes, in common with many teachers, I share comments on students' work in writing - marking them on submitted assignments or drafts; and sometimes I even do so in awful red pen. However, I much prefer to let them know what I think of their work in discussion, especially when I am offering feedback on work in progress. More than that, I favour feedback sessions with whole classes, rather than individual feedback, which puts me at odds with many colleagues who believe that to give feedback in a class setting is unhelpful because it could be embarrassing for a student to have her weaknesses discussed in front of others. Indeed some colleagues have even accused me of unethical conduct when I confess to this aspect of my pedagogic practice, though interestingly, those who have seen it in action seem to have a different view.

Sensitivity to students' feelings is laudable. However, I think it is a mistake to allow the possibility that students might take offence to dictate how and when you should deliver feedback, because given a certain degree of kindness on your part, sharing feedback about students' work in a group, is nearly always a positive experience. I find this is the case, even when the feedback I am offering relates to the work of particular individuals. In any case, I always try to focus feedback mainly on mistakes that a number of students have made, and I never directly address the author of a mistake when I discuss it with a group, unless they identify themselves, which they very often do, perhaps because they recognise that I am trying to help and they want to get as much help as they can.

\section{Knowing what you know (and what you don't)}

In my experience students find it helpful to know that they are not the only ones who lack particular skills or knowledge, or who have made particular mistakes. For one thing, it gives them permission to avoid engaging in the kind of pretence that the Scottish psychiatrist R.D. Laing pointed out when he summed up the experience of the intellectual and emotional tangles in which many people become involved, in trying to avoid exposing their ignorance: 
There is something I don't know

that I am supposed to know.

I don't know what it is I am supposed to know,

and yet I am supposed to know,

and I feel I look stupid

if I seem both not to know it

and not know what it is I don't know.

Therefore I pretend I know it.

R. D. Laing, (Knots, 1970, p.56)

Do you ever pretend to know what you don't know? Do you think that your students do? Do you think that they ever pretend to understand what they don't understand?

Or are your students brave enough - wise enough - to ask for help when they are uncertain, whether their uncertainty is about a piece of knowledge or skill, or just about their confidence in their ability? If they aren't, I think it is important that you spare no effort in the attempt to persuade them that since their job is to learn, even at the expense of admitting that they don't know, the sooner they learn to admit that at times they don't know and understand, the better. To attempt to avoid looking foolish in front of their peers by pretending that they understand when they don't, is just about the most stupid thing that a student can do, while honestly admitting to ignorance, thus opening themselves to the possibility of learning, is probably the most important thing they can learn to do.

One of the best things that we can teach our students, whether, for example, they are children, adult learners or postgraduates, is that it is OK to be unsure about things, and that knowing that they don't know is a sign of strength rather than a sign of weakness. One way we might do this is by teaching in a way that makes it clear that we don't know everything that there is to know about anything. I find that this sits very easily with me, since by comparison to the vast amount of accumulated knowledge in the world, I readily admit to knowing comparatively little, even in relation to areas in which others might be inclined to believe that I have expertise. Another way we can teach our students that admitting to a lack of understanding or knowledge is $\mathrm{OK}$, is by engaging them in supportive discussion of one another's work, whether in tutorials, or in feedback sessions in larger classes, of the kind that I have discussed above. 
Of course, there are occasions when private, one-to-one feedback is called for. However, I believe that it is a very good practice for teachers at all levels from the early years of school to postgraduate level, to give at least some feedback in the context of a class discussion, because this allows them to draw attention to shared and common problems in an efficient way. This belief relates closely to my strongly held view that supervision of student research at all levels, from undergraduate dissertation to $\mathrm{PhD}$, is best when it is conducted in a group, preferably with students focusing on a range of research topics.

\section{Working on students' texts with them}

The second area of my pedagogic practice I want to raise, relates to the ways in which I try to help students to develop their skill as academic writers. Here, I find that rather than responding to drafts on paper, 'marking up' their text as a copy-editor would, noting errors and making suggestions for improvements, it is far more productive to work with them, either individually or in a group, on drafts of their work. I know from experience, as you probably do, how soul destroying it can be to receive work back from another person covered in suggestions and questions and remarks. And I know, from a great deal of experience, how much my own writing benefits from occasions when friends and colleagues sit and read my work with me, suggesting as we do so, ways in which I might say what I want to say more clearly and concisely, or in more engaging ways.

I think the reason that this is helpful is that other people are almost bound to read my work differently than me, because they didn't write it. As a result, provided they take the task seriously, rather than 'skip-reading' to get a general sense of what I am on about, they are less likely to read over mistakes than I am. After all, as the author of my text, I was present at its birth; I am its mother and father. I know what I was trying to say, which is why it is so likely that I will 'read' my own written work as if it says what I was thinking as I wrote, even when it doesn't. That is why it is important for developing writers like me - and you, and like our students - to develop the habit of always copy-editing our written work as if it was written by someone else; it is just too easy otherwise, to read what we think we wrote rather than what we actually wrote, and hence to fail to pick up mistakes.

My preferred way of facilitating students' development as writers is to work with them on their texts, whether they are essays or other assignments; dissertations or theses. 
Typically this involves jointly reading the student's text and modelling, in discussion, how we might interrogate it in an effort to see where changes might make it clearer. During this process I support the student in the attempt to frame changes that move the text forward strengthening arguments; restructuring, and recasting ideas in ways that aid clarity. This usually involves not only working with paper copies of their work, but working with the text 'live' on a computer, trying out different ways of saying things; moving text about; substituting words; restructuring paragraphs and so on. I discuss the process of live editing in a group in an earlier opinion piece (Fairbairn, 2011).

I find that entering into a kind of partnership with students, in exploring and working a little on their texts, is the least threatening way to help them to become more careful writers. My main aim in this is to enable them to develop the ability to read their own work as if they were not familiar with what it is supposed to be saying, and then to find ways of amending it so that it conveys more easily, more engagingly and more fluently, what as an author, they wanted to say.

\section{Does helping a student to develop her text amount to cheating?}

I am conscious that many teachers will view some of what I have written in the last paragraph with alarm. They might even view my suggestion that teachers should contribute directly to the drafting of students' written work as support for a form of cheating, and this is something that has occasionally been suggested by colleagues. After all, I have talked about 'entering into a kind of partnership' with students as we work on their texts together, almost as if I am suggesting that for that time, I become a co-author, a co-worker. Actually that is exactly what I am suggesting, because I believe that working alongside someone with more advanced skills is the best way to grow in any trade.

The apprenticeship approach to learning has a long history, and the idea of apprenticeship has been adopted quite widely in educational thinking in recent years. I dare say that in most trades, apprentices have always had a helping hand in building or creating or making, from someone with more skill. But just as a brick wall, a grave stone, a stained glass window or a perfectly formed loaf of bread, is the product of an apprentice's labour, even when the mark of a master craftsman can be detected in some element of the finished product, when I assist a student to refine a piece of writing, the end product is 
theirs, even when it carries my influence. The same is true when I offer advice and support to colleagues who are writing for publication (and as much of my work of this kind is carried out with professional academics as it is with students). Harwood et al. (2010) discuss related issues in a helpful way in the context of their study of the wide range of thorny ethical issues that surround the practice of students purchasing the services of paid and unpaid 'proofreaders' as a way of improving their academic work before submission. However, it is important to draw attention to a significant difference between the practice in which I engage (and which I would like to promote) when I am helping students to develop their texts, and the use, by students, of 'proofreaders'. Whereas my approach is a development of my function as a role model for fledgling academics, intended to change how they think and how they behave, the role of the 'proofreader' is to make-up for the deficiencies in the student, with the aim of gaining them better marks in a particular assessment.

Contributing a form of words or suggesting a way of re-structuring a text, is no more cheating than the attempt to induce a change in what a student has written by pointing out that a sentence is 'ungrammatical', 'unclear', 'irrelevant' or 'makes no sense'; that a point is 'poorly argued' or an essay 'badly structured'. It is just more supportive and therefore more likely to help a student to improve both her writing and her approach to writing. Of course, where I have supported a student in developing a text, if ideas that I introduced to them appear in the completed work - whether it is an essay or dissertation, I would expect to be cited, just as I would expect a colleague to acknowledge the part I had played in helping them to develop an article or conference paper.

\section{Concluding remarks}

In this short article, I have shared a couple of areas of my practice as a teacher that some colleagues find surprising and which some even find ethically questionable. I would be interested to hear what readers of the Journal of Learning Development in Higher Education think of them, and especially about whether others engage in similar practices or eschew them because they consider them to be ethically questionable. 


\section{References}

Fairbairn, G. (2011) 'Academic writing masterclasses: 'shared live editing' in a group', Journal of Learning Development in Higher Education, Issue 3, March, pp. 1-6.

Harwood, N., Austin, L. and Macaulay, R. (2010) 'Ethics and integrity in proofreading: findings from an interview-based study', English for Specific Purposes, 29(1), pp. 54-67.

Laing, R.D. (1970) Knots, London: Penguin.

\section{Author details}

Gavin Fairbairn is Professor of Ethics and Language at Leeds Metropolitan University, whose work in both areas is underpinned by his belief in the value of storytelling. In the past, after a career in special education and many years as a teacher educator, he was Professor of Professional Development in Nursing and Midwifery at the University of Glamorgan, then Professor of Education at Liverpool Hope. His research and professional activity is focused in two areas: applied ethics and philosophy, especially in relation to health, social care and reconciliation after conflict, and the development of academic and professional writing. 